\title{
Embedded Based Vehicle Security using GSM -and GPS System
}

\author{
Dinesh Magar', Sanket Gadge ${ }^{2}$, Shraddha Gadakh³, Prof. Seema S. Lavate \\ Student, Electronics Department, PREC, Loni, India ${ }^{1,2,3}$ \\ Assistant Professor, Electronics Department, PREC, Loni, India ${ }^{4}$
}

\begin{abstract}
Now a days every individual is preferring to use own vehicle for transportation rather than public transportation because of flexibility in schedule. However a vehicle thefts are increasing in parking and public places. Various Systems are developed for attempting this issue. Thepreviously reported systems provide the solution for communication between owner and vehicle GSM unit and sending password SMS and informing exact location of vehicle. The proposed system is used for security purpose. If any unauthorised person try to theft the vehicle then the system has a password using for ignition start of the vehicle .if any unauthorised person try to theft it then he has to enter password. If he enter password three times wrong then identify message will be send to owner and driver about the car theft under prosses and location of car. The system also has facility to lock the wheel and vehicle stop ignition and also new password will be send and set for vehicle.
\end{abstract}

Keywords: GSM, Vehicle security, GPS.

\section{INTRODUCTION}

In these days, automobile thefts are expand at an alarming rate all over the world. So to escape from these thieves most of the vehicle owners have started using the theft control systems. The commercially available anti-theft instrument based on PIC controller and operated using GSM technology. The instrument is simple and low cost vehicle theft control embedded system. The GSM is more popular and accepted standard for mobile phones in the world established in 1982. Vehicle tracking systems have brought this technology to the day-to-day life of the common person. In the past decades, India has progress such a massive rate that many companies have effectively established at this position. These companies are bringing a vast amount of labour force with them. They are arranging transportation to such a vast mass is a bulky job involving many details.

Generally, this transport is organised during the local transport vendor on once a year agreement basis, just now take place mishaps, such as stealing, rape etc. The increase of satellite communication technologies is easy to discover the vehicle locations with no trouble.The GSM/GPS system is incredibly necessary everybody in regular life, which has integrated each GSM and GPS technologies. it's necessary as a result of the cluster of applications both GSM and GPS systems that the wide usage by uncountable voters everywhere the globe. These systems supposed to be used in land production and transport supply period data for example place, speed and certain point of the user is moving vehicle within the concise and mobile formats.

\section{PROPOSED SYSTEM}

In this proposed system ARM 2138 microcontroller is used for logic implementation. If unauthorized person tries to attempt for starting vehicle it can be detected by password mechanism and GSM module used for sending password information with status of vehicle along with exact position of vehicle given by GPS unit. In this proposed work, a new method of advanced vehicle system is implemented, which is used to track the theft vehicle by using GPS, GSM technology and also provide voice alarm system.Systems are developed for attempting this issue however previously reported systems provide the solution for communication between owner and vehicle GSM unit. There is a need of system for sending password SMS and informing exact location of vehicle along with locking of vehicle if wrong password entry detected.

\section{III.DETAILED DESCRIPTION}

The Vehicle positioning System consists of ARM System GSM module GPS module LC and the keyboard, DC motor Battery. 


\section{International Journal of Innovative Research in} Electrical, Electronics, Instrumentation and Control Engineering

ISO 3297:2007 Certified

Vol. 5, Issue 4, April 2017

\section{Hardware}

1. Microcontroller: -ARM7 (LPC 2138)

2. LCD: $16^{*} 2$ Alphanumeric Displays

3. RS232: MAX 232 IC

4 Total systems Power Supply: 12 v, 1 Amp current.

5. Relay- 12 volt

6. Keypad- $4 \times 4$

7. GPS modem

8. GSM modem

\section{BLOCK DIAGRAM OF THE SYSTEM}

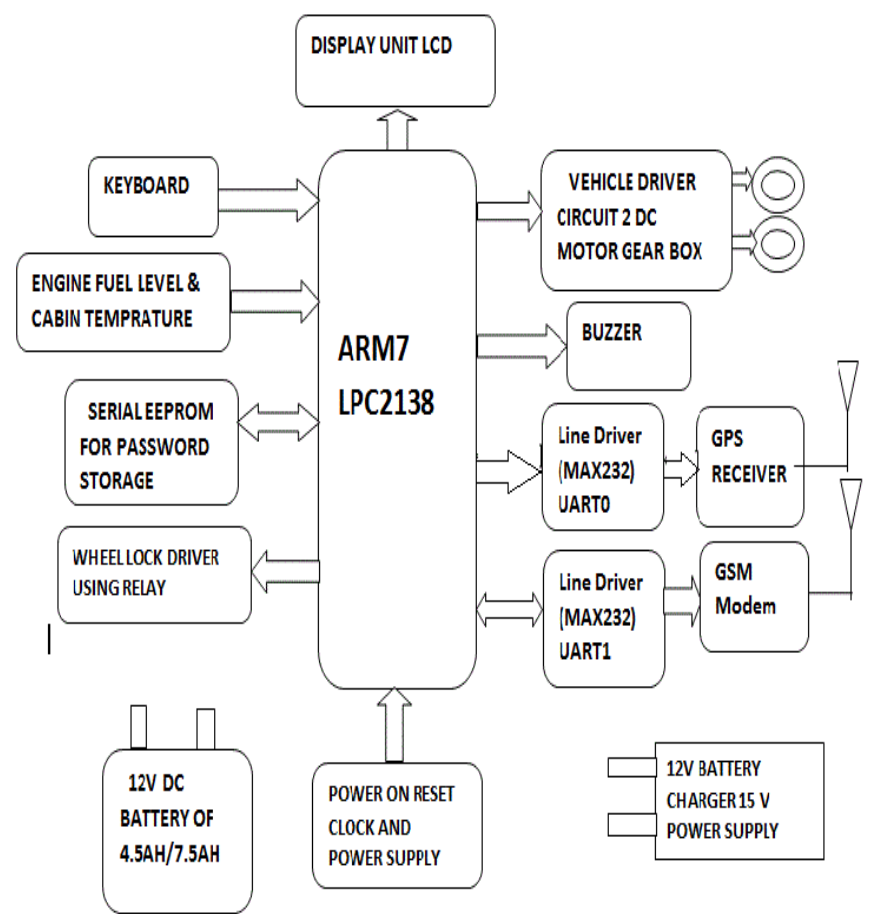

Fig.1 Block diagram of the system

\section{IV.WORKING OF THE SYSTEM}

The embedded system installed in engine of the vehicle along with the GPS/GSM modem by entering a correct password the instrument allows to activate the $12 \mathrm{~V}$ relay and then ignition of the engine will start. Hence start the vehicle. If anyone tries to enter the password randomly, then after three trials, The MCU will block the entry of further password. Then, the buzzer will have turned on to create a noise to panic the culprit, followed by sending a message "Alter: Car Is Under Threat, and location of car" through GSM modem to owner's mobile for further action for prevention of his vehicle.According to prototype model after entering correct password the car will move and at the same time, according to instruction it will run forward reverse, left or right as per command. The source code is written in embedded $\mathrm{C}$ language and compiled using Kiel-4.

\section{GSM modem}

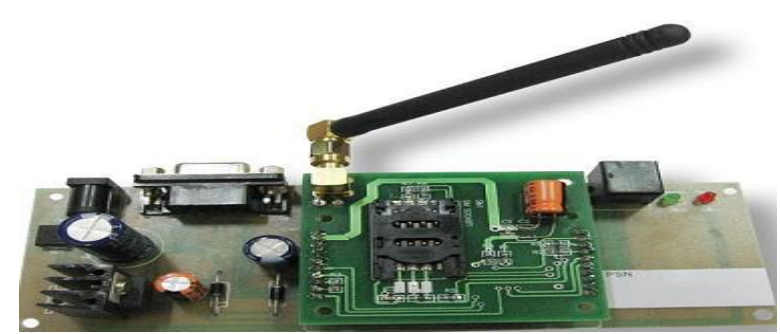

Fig.2 GSM modem 
GSM (Global System for Mobile communication) could be a digital mobile telecommunication system. With the assistance of GSM module interfaced, we will send short text messages to the desired authorities as per the applying. GSM module is provided by SIM uses the mobile service supplier and send SMS to the individual authorities as per programmed. This technology permits the system a wireless system with no suchvarylimits.New improved GPS Module with constitutional antenna and memory back-up for OEM and hobbyists comes. This unit options low power consumption, high sensitivity. The unit is good for navigation systems, distance measurements, vehicle observance and recording, water travel direction and site, along side hiking and raceexploring. This module includes high exactitude surface mount technology to produceeach high accuracy and really compact size. The module issimplyput in on a main board, with all inputs victimizationcommonplace TTL signal levels.

\section{GPS MODULE}

New improved GPS Module with inherent antenna and memory back-up for OEM and hobbyists comes. This unit options low power consumption, high sensitivity. The unit is right for navigation systems, distance measurements, vehicle watching and recording, seafaring direction and placement, beside hiking and raceexploring. This module includes high preciseness surface mount technology to supplyeach high accuracy and really compact size. The module are oftensimplyput in on a main board, with all inputs victimizationnormal TTL signal levels

\section{Circuit Diagram of the system}

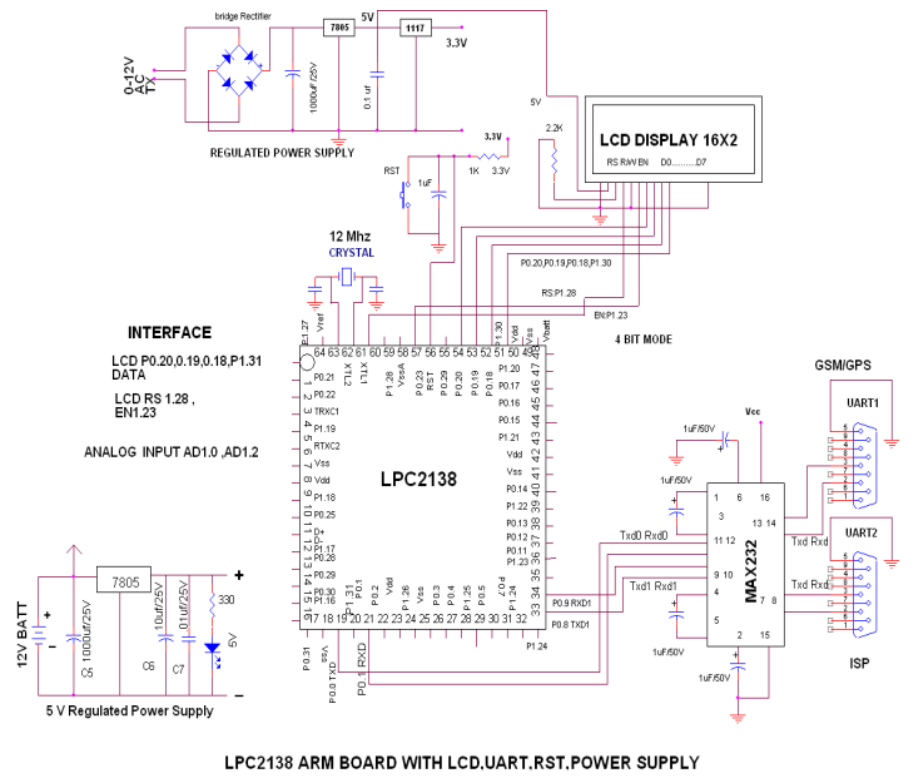

Fig. 3 Circuit diagram of the system

\section{SOFTWARE INFORMATION}

OrCAD: OrCAD is a proprietary software tool suite used primarily for electronic design automation (EDA). This software used mainly through electronic design engineers and electronic technicians to create electronic schematics and electronic prints for manufacturing printed circuit boards.

\section{Kiel-4 for controller:}

The $\mu$ Vision editor and programmear integrated in a very single application that gives a seamless embedded project development setting. The $\mu$ Vision IDE (Integrated Development Environment) is that theeasiest methodfor many developers to form embedded applications exploitation the Keil development tools.

\section{Protel:}

Protel stands for "Procedure boundsortimposing Language". it's a programing language created by Nortel Networks and used on telecommunications change systems like the DMS-100Kiel-4 for controller: The $\mu$ Vision editor and programmear integrated in an exceedingly single application that gives a seamless embedded project development surroundings. The $\mu$ Vision IDE (Integrated Development Environment) is that theeasiest methodfor many developers to make embedded applications victimisation the Keil development tools. 


\section{International Journal of Innovative Research in} Electrical, Electronics, Instrumentation and Control Engineering

ISO 3297:2007 Certified

Vol. 5, Issue 4, April 2017

\section{Algorithm}

1. Initialize LCD, GSM and Timer.

2. Using keypad Enter password (0-9 four digits only).

3. Compare password with system.

4. If password wrong, then send SMS on stored mobile number and also lock the wheel.

5. If password is valid, enter command and vehicle start ignition.

6. Read engine status, fuel level and door locking.

7. Display value on LCD of fuel level, cabin temperature \& location status.

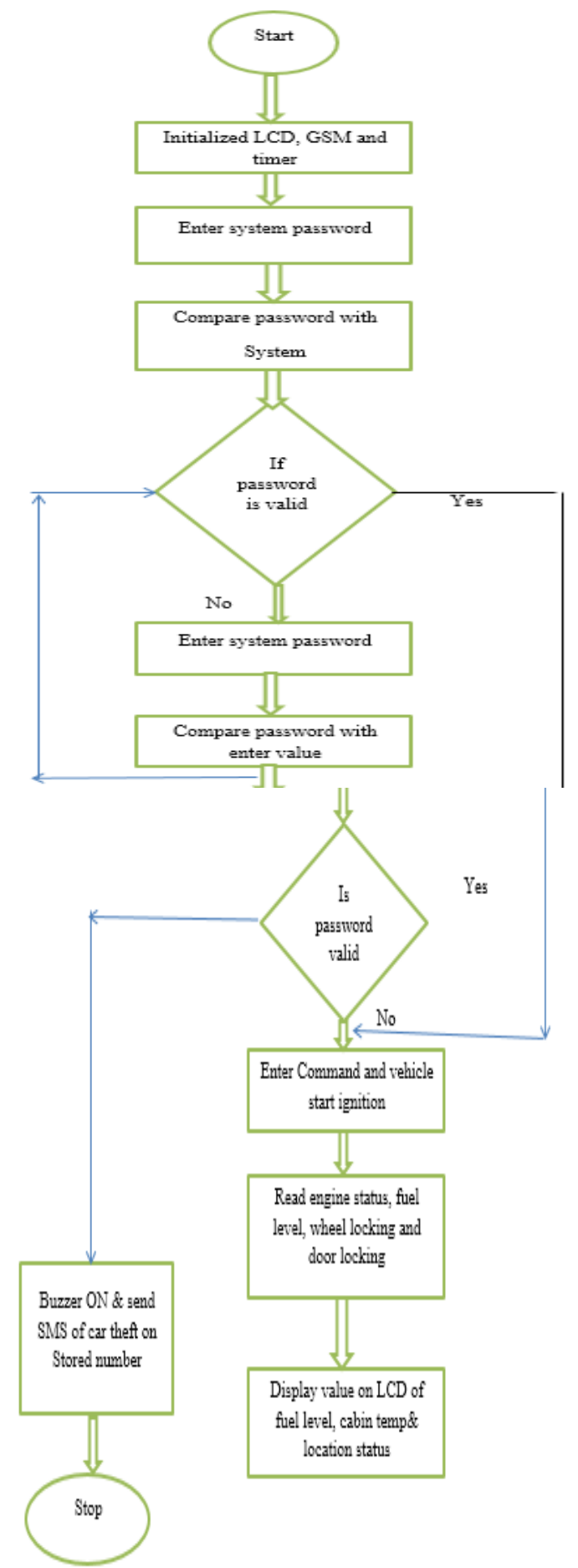

Fig. 4. Flow chart of Proposed System 


\section{IJIREEICE \\ Vol. 5, Issue 4, April 2017}

\section{APPLICATION}

\section{1. for Personal Vehicle:}

The proposed system can be used for a personal vehicle in which immediate help can be provided using SMS details to the vehicle fitted with thissystem. If any unfortunate accident occurs, the victimized car can be tracked using GPS technology.

\section{Military Applications:}

Military vehicles carry ammunition from one place to another. Conspiracy hatchers, who know about this fact, may attack such vehicles, in order to either steal the arms or simply destroy them. In order to controlled the loss caused in this way, military vehicles can be fitted with this system. If the vehicle got attacked or damaged, an immediate SMS is sent to military base station and these ammunitions can be saved from reaching the wrong hands.

\section{Research and Development of Vehicle:}

For testing the vehicle in $\mathrm{R}$ and $\mathrm{D}$ an engineer requires data about the vehicle at various speed and time but this data is not available exactly as it is not possible to measure the data for every second and to measure the number of parameters at the same time. But if this suggest system is used.the data can be made available for each and every second with very high accuracy. With the help of any software.the data can be plotted in graphical form of speed Vs time, and engine temperature Vs. time.

\section{CONCLUSION}

In this project we have proposed a vehicle tracking, wheel locking systems. Track the theft vehicle by using GPS and GSM technology. This system puts into vehicle handled by the owner or authorized persons, otherwise goes to active mode. The mode of performanc changed by persons or remotely. When the theft recognized, the responsible people send SMS to the micro controller, then matter the control signals to stop the engine motor.

\section{RESULT}

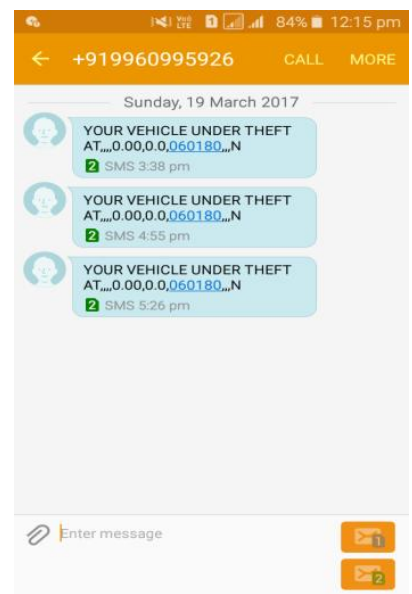

Fig.5 Result of the location

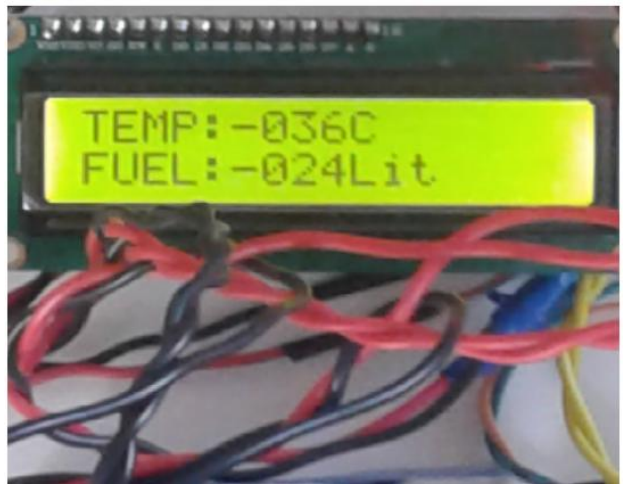

Fig.6 Display temp and fuel level 


\section{IJIREEICE \\ Vol. 5, Issue 4, April 2017}

In the system password for vehicle ignition is set. The driver known that password is anybody is in process of theft then by any means if he enters in vehicle then he has to enter the password. If passwords match then the ignition of vehicle permitted other. If the person enter three times wrong password then the above message (result fig.) send to driver and owner. If by any other that is vehicle under theft then owner gets message and he can change the password through the SMS and stop the vehicle.

\section{REFERENCES}

[1] Saloni Shah, Siddhi Patel, Prof. Harish Narula, "Intelligent Vehicle Theft Control using Embedded System" International Journal of Computer Applications (0975 - 8887) Volume 107 - No. 19, December 2014

[2] Jayanta Kumar Pany\& R. N. Das Choudhury“Embedded Automobile Engine Locking System, Using GSM Technology” International Journal of Instrumentation, Control and Automation (IJICA) ISSN : 2231-1890 Volume-1, Issue-2, May 2011

[3] Pritpal Singh, TanjotSethi, BibhutiBhusanBiswal, and Sujit Kumar Pattanayak, "A Smart Anti-theft System for Vehicle Security" International Journal of Materials, Mechanics And Manufacturing, Vol. 3, No. 4, November 2015

[4] M. S. Joshi and D. V. Mahajan, "Arm 7 based theft control, accident detection and vehicle positioning system," International Journal ofInnovative Technology and Exploring Engineering, vol. 4, no. 2, pp. 29-31, July 2014.

[5] M. A. A. Khedher, "Hybrid GPS-GSM localization of automobile tracking system," International Journal of Computer Science andInformation Technology, vol. 3, no. 6, pp. 75-85, Dec 2011.

[6] S. S. Pethakar, N. Srivastava, and S. D. Suryawanshi, "RFID, GPS and GSM based vehicle tracing and employee security system," International Journal of Advanced Research in Computer Science and Electronics Engineering, vol. 1, no. 10, pp. 91-96, Dec. 2012.

[7] V.Ramya, B. Palaniappan, K. Karthick, "Embedded Controller for Vehicle In-Front Obstacle Detection and Cabin Safety Alert System", International Journal of Computer Science \& Information Technology (IJCSIT) Vol 4, No 2, April 2012.

[8] Chen Peijiang, Jiang Xuehua, "Design and Implementation of Remote monitoring system based on GSM," vol.42, pp.167-175. 2008.

[9] Albert Alexe, R.Ezhilarasie, "Cloud Computing Based Vehicle Tracking Information Systems”, ISSN: 2229 - 4333 ( Print) | ISSN: 0976 - 8491 (Online ) IJCST Vol. 2, Issue 1, March 2011

[10] KunalMaurya, Mandeep Singh, Neelu Jain, "Real Time Vehicle Tracking System using GSM and GPS Technology- An Anti-theft Tracking System," International Journal of Electronics and Computer Science Engineering. ISSN 2277-1956/V1N3-1103-1107 